\title{
HIGH-GRADE CENTRAL MUCOEPIDERMOID CARCINOMA ARISING IN AN ODONTOGENIC CYST: A CASE REPORT AND REVIEW OF THE LITERATURE
}

\author{
Paweł Świerzy ${ }^{1}$, Mariusz Szuta ${ }^{2}$, Romana Tomaszewska ${ }^{3}$, Jadwiga Stypułkowska ${ }^{1}$, Hiba Alobaide ${ }^{4}$, Marta Świerzy ${ }^{5}$, \\ Tomasz Kaczmarzyk ${ }^{6}$
}

'Department of Oral Surgery, University Dental Clinic, Cracow, Poland

2Department of Craniomaxillofacial, Oncologic, and Reconstruction Surgery, Jagiellonian University School of Medicine, Cracow, Poland ${ }^{3}$ Department of Diagnostic Pathomorphology, University Hospital of Cracow, Poland

${ }^{4}$ Students' Scientific Circle at the Department of Oral Surgery, Jagiellonian University School of Medicine in English, Cracow, Poland

${ }^{5}$ Department of Orthodontics, Voivodeship Dental Polyclinic, Cracow, Poland

${ }^{6}$ Department of Oral Surgery, Jagiellonian University School of Medicine, Cracow, Poland

\begin{abstract}
Central mucoepidermoid carcinoma (CMEC) is a very rare neoplasm comprising $2 \%$ to $4 \%$ of all mucoepidermoid carcinomas. We herby present an unusual case of high-grade CMEC of the maxilla of a 53-year-old male patient, who was referred to the Department of Oral Surgery by a general dentist due to accidentally detected on X-ray unilocular radiolucent lesion on the premolar region of the left maxilla. Intraoral examination revealed asymmetry of the vestibule with palpable swelling in the region of 24-26 with a positive fluctuation and crepitation. After CBCT examination and core needle biopsy, preliminary diagnosis of residual cyst was made, and the cystic lesion was excochleated. Histopathological examination revealed a high-grade CMEC. Patient was reported to the Department of Cranio-Maxillofacial Surgery, where he underwent a subtotal maxillectomy and selective neck dissection. The patient remains in follow-up, having had no recurrences during 12-month period after surgery.
\end{abstract}

KEY wORDS: mucoepidermoid carcinoma, radicular cyst, residual cyst, odontogenic cyst, oral surgery.

J Stoma 2018; 71, 4: 365-372

DOI: https://doi.org/10.5114/jos.2018.83411

\section{INTRODUCTION}

Mucoepidermoid carcinoma (MEC) was first described in English literature by Stewart et al. in 1945 [1]. Yet, in 1939, Lepp and his team were the first to report central mucoepidermoid carcinoma (CMEC) of the mandible in a 66-year-old female patient [2].

MEC constitutes 5-10\% [3] of all salivary gland carcinomas and is mostly located in the parotid salivary gland
(89.6\% of all documented cases). It can also be found in the submandibular $(8.4 \%)$ or in the sublingual gland (0.4\%) [3], but considerably less often. Despite the fact that MEC is the most common salivary gland carcinoma, its intraosseous variant (CMEC) appears extremely rarely and represents only $2-4.3 \%$ of all MEC cases [4].

CMEC affects women twice as often as men [5, 6]. It has been reported in all age groups, but it is usually diagnosed in the $4^{\text {th }}$ and $5^{\text {th }}$ decade of life $[3,5]$. It presents three [7]

JOURNAL OF STOMATOLOGY CZASOPISMO STOMATOLOGICZNE

ADDRESS FOR CORRESPONDENCE: Tomasz Kaczmarzyk,

Department of Oral Surgery, Jagiellonian University School of Medicine,

4 Montelupich St., 31-155 Krakow, Poland,

e-mail: tomasz.kaczmarzyk@uj.edu.pl 
or even four times $[6,8]$ more often in the mandible than in the maxilla, mostly on the lateral part of the mandibular body or in the vicinity of the mandibular angle [9]. Forty percent of reported CMEC cases accompanied an odontogenic cyst and/or an impacted tooth. Thirty-one percent of them did not present any concomitant pathology [6].

Pathogenesis of this lesion is not fully known, although there are some theories suggesting its origin such as: a neoplastic transformation of the maxillary sinus epithelium with the tumor herniation in the maxilla, a malignant transformation of a minor ectopic salivary gland dislocated into the bone, or a neoplastic transformation of mucus-secreting cells, which are common in pluripotent epithelial lining of odontogenic cysts, especially of dentigerous type $[3,6,8,12]$.

This report presents a case of a 53-year-old male, who was diagnosed with high-grade central mucoepidermoid carcinoma located in the alveolar process of the left maxilla and was arising in the epithelial lining of an odontogenic cyst.

\section{CASE REPORT}

A 53-year-old male was referred by general dentist to the Department of Oral Surgery due to a cystic lesion

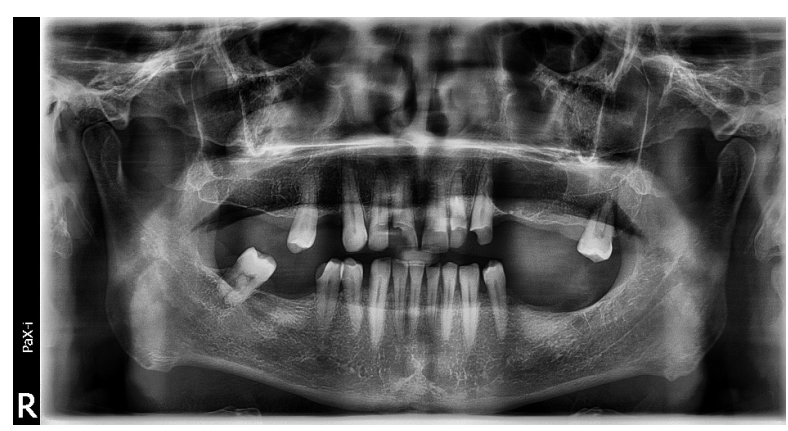

FIGURE 1. Orthopantomogram of the left maxilla. The lesion had been coincidentally detected during a routine panoramic radiograph (Figure 1). The patient did not complain of any pain in that area. The teeth located in the vicinity of the lesion had been extracted many years before due to an advanced stage of dental caries. The patient did not report any diseases in his medical history.

On extraoral examination, no elevation, changes in facial symmetry, or palpable lymph nodes were detected. Intraoral examination showed a visible asymmetry in the oral vestibule, which was caused by an intraosseous expansion near the teeth 24-26. Palpable examination revealed a symptom of crepitation, along with some fluctuant areas.

Panoramic radiograph showed osteolytic bone lesion distal to the decayed tooth 23 , which encompassed the floor of the alveolar recess of the left maxillary sinus and reached the alveolar process of the left maxilla to the area of tooth 26. The patient was referred to CBCT scan in order to define the exact size of the lesion and its potential invasion into the maxillary sinus as well as to plan a surgical intervention.

CBCT scans showed a lesion of $21 \times 18 \times 17 \mathrm{~mm}$, which did not invade the left maxillary sinus (Figure 2).

Under superficial anesthesia, a diagnostic puncture was performed, and $2 \mathrm{ml}$ of brownish liquid was aspirated which, when checked against the light, revealed opalescence of cholesterol crystals - typical for an odontogenic cyst. Consequently, the presence of either radicular or residual cyst was initially diagnosed, and a complete enucleation of the lesion was planned. Under infiltration anesthesia, a mucoperiosteal flap was created in the oral vestibule right over the bony elevation, next to the previously extracted teeth 24-25. It exposed a capsule of the cystic lesion covered with small fragments of the bone lamella of the alveolar process of the left maxilla (Figure 3). The cyst was enucleated completely

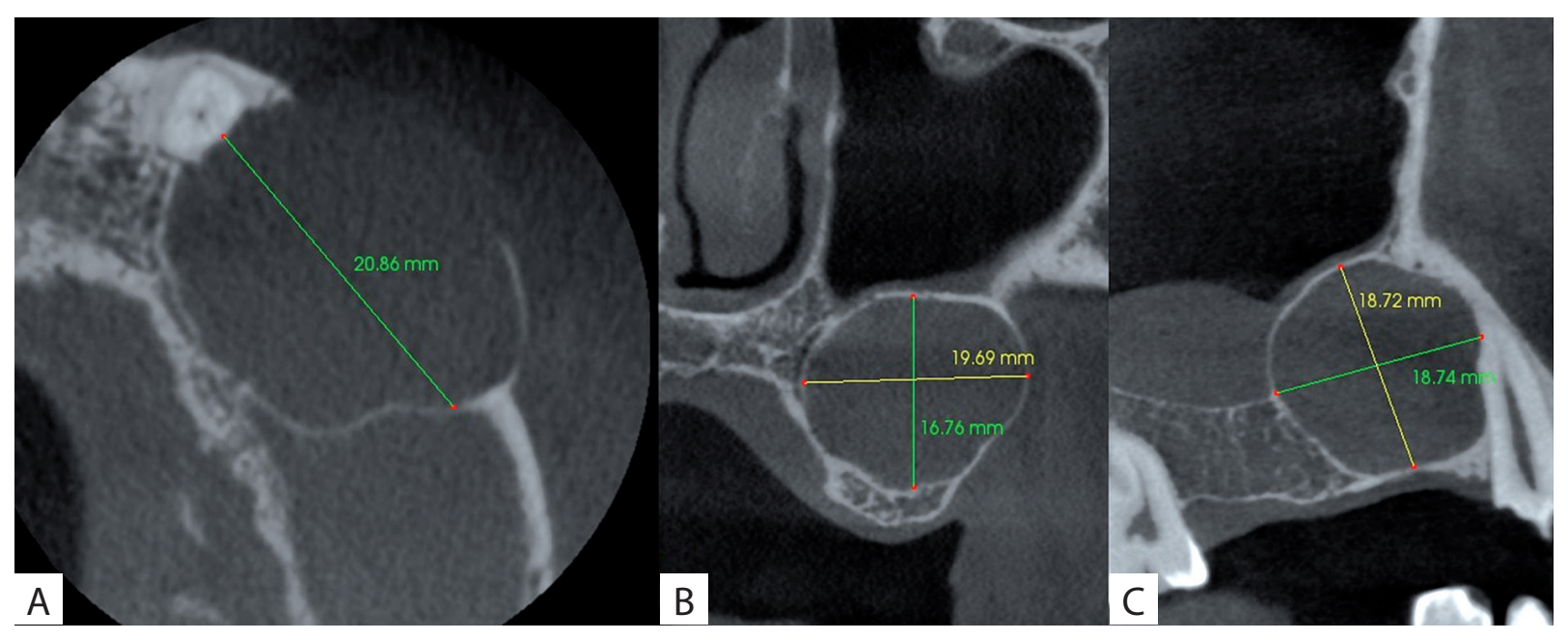

FIGURE 2. Cone beam computed tomography scan: A) horizontal plane, B) frontal plane, C) axial plane 


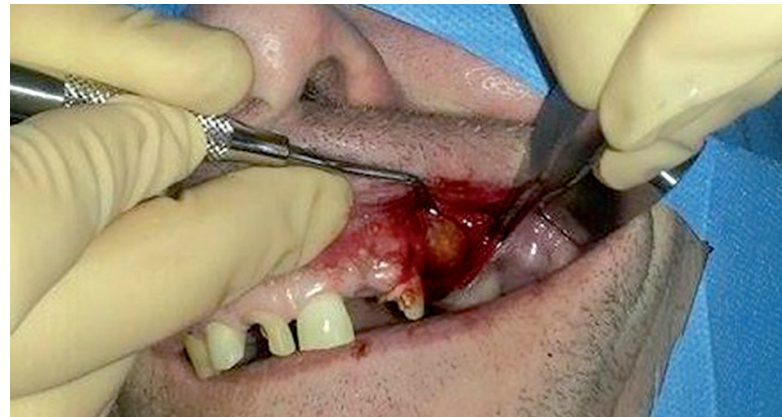

FIGURE 3. Intraoral view after elevation of periosteal flap during surgery

(Figure 4) and the specimen was sent for histopathological examination.

The examined sample contained a fibrous, mostly thin-walled cyst, which had a significant thickening in one of its poles (Figure 5). In the cyst wall, small hemorrhages were present along with focal concentration of scattered lymphocytes and small fragments of trabecular bone. Additionally, the thickened wall contained hemosiderin pigment and cholesterol clefts. In some places, the cyst lining was thin, made of a few layers of regular epithelial cells (e.g., thinned stratified squamous epithelium) with significant stratum basale (Figure 6). In other regions, the lining included more layers of epithelial cells with distorted polarization and polymorphic, enlarged hyperchromatic nuclei as well as multiple mitotic figures (Figure 7). Rare mucus-secreting cells were present among epidermal cells. In the vicinity of the thickened cyst wall there were numerous nests of epithelial cells, both epidermal and intermediate type, which contained rare mucus-secreting cells and small "pools" of extracellular mucus (Figures 8 and 9). The cells presented significant atypia and multiple mitotic figures. Epithelial nests in the center were undergoing necrosis infiltrated by neutrophils. Histological image of the examined lesion revealed high-grade central mucoepidermoid carcinoma arising in an odontogenic cyst.

Having received the results of histopathological examination and due to the risk of a non-radical approach, the patient was referred to the Department of Craniomaxillofacial Surgery to extend surgical procedure. Here, following the head and neck oncological council consultation, the patient was qualified for a radical surgery and possible adjuvant radiotherapy.

Diagnostic imaging performed before the surgery included a spiral CT scan of the facial skeleton. It showed that the cavity after the cyst enucleation of size $17 \times 21 \times 18 \mathrm{~mm}$ contained a mural tissue build-up, visible after strong contrast enhancement. However, it did not infiltrate nearby structures (Figure 10). Additionally, the scan depicted thinning of bony rims along with the after-surgery bone lamella defect from the buccal

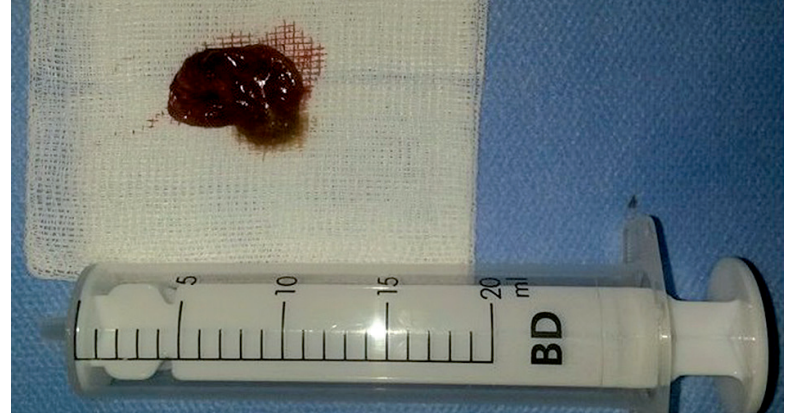

FIGURE 4. Surgical specimen of enucleated cyst

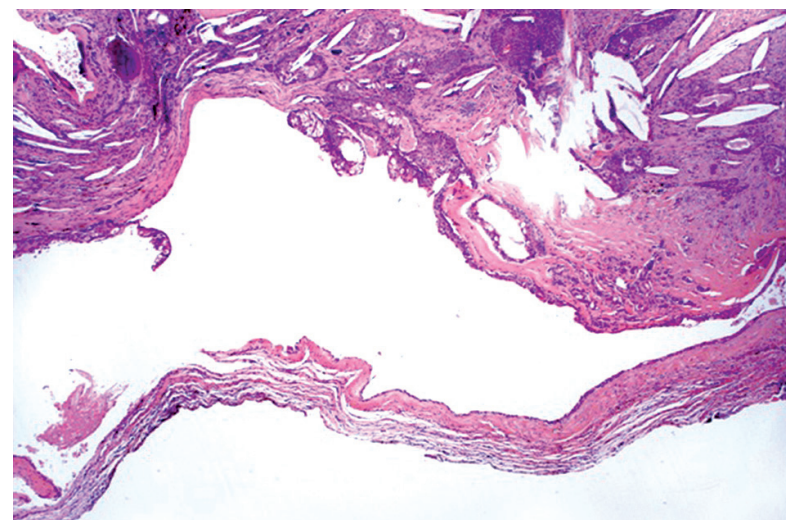

FIGURE 5. The low-power view shows the cystic lesion with cancer infiltrating the upper right-hand corner. HE $50 x$

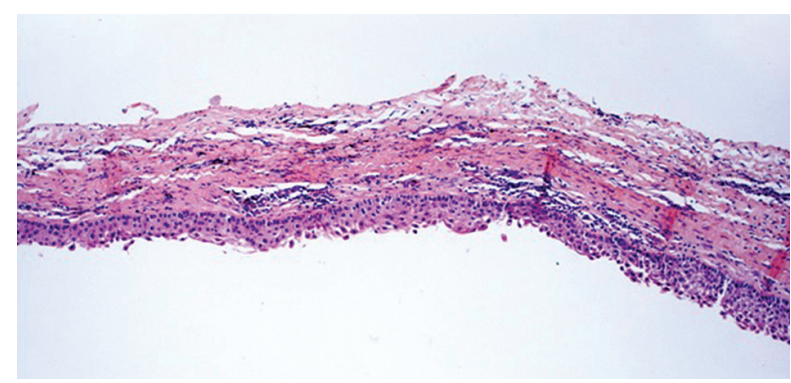

FIGURE 6. The wall of the odontogenic cyst lined by moderately dysplastic epithelium. HE 100 x

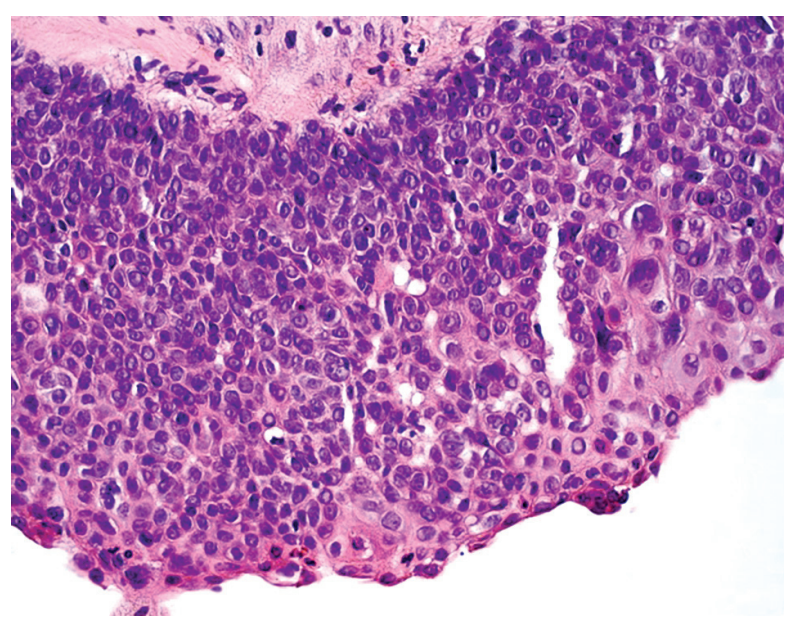

FIGURE 7. The epithelial lining shows signs of severe dysplasia. HE $400 x$ 


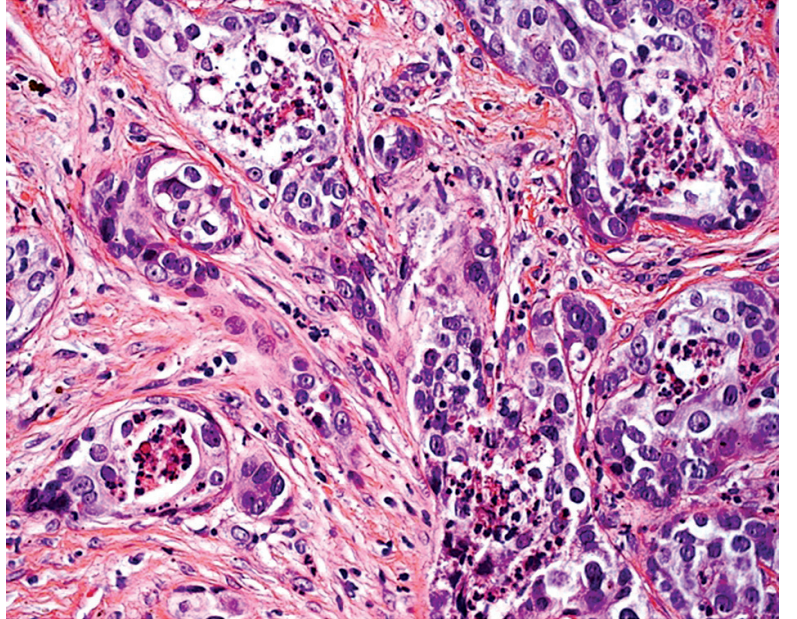

FIGURE 8. The epidermoid and intermediate cell component of the mucoepidermoid carcinoma. The nuclei are highly atypical. HE $200 x$
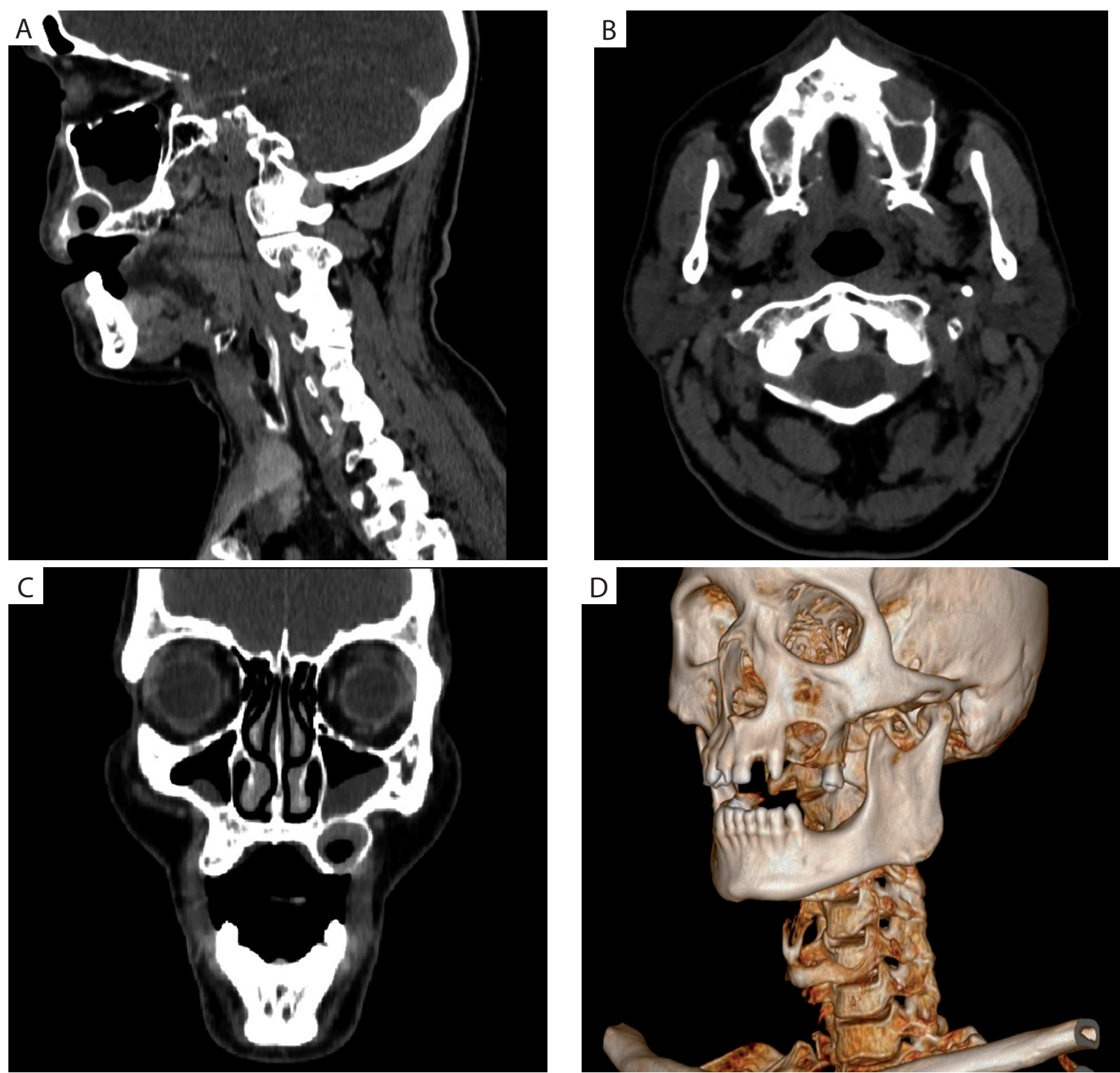

FIGURE 10. Spiral computed tomography scan before partial left maxillectomy: A) axial plane, B) horizontal plane, C) frontal plane, D) 3D reconstruction 


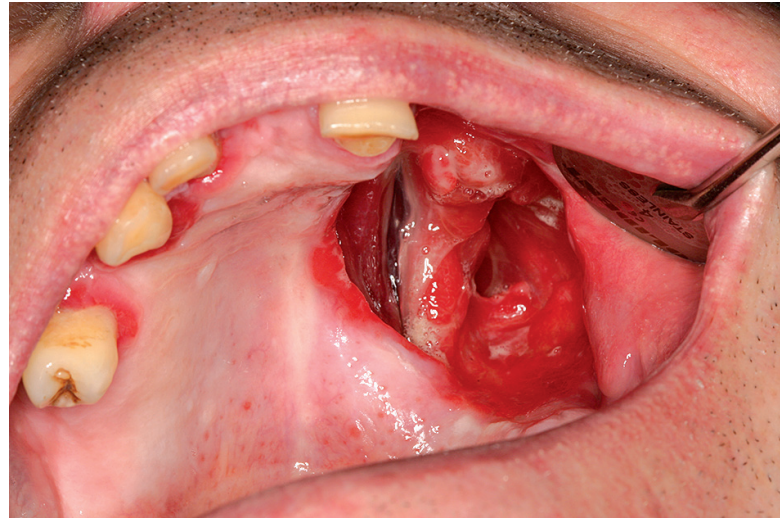

FIGURE 11. Intraoral view after partial intraoral left maxillectomy

side. Atypical lymph nodes visible without strong contrast enhancement were detected perivascularly and bilaterally on the neck. The maximum size was $11 \mathrm{~mm}$ in short axis with preserved fatty hila.

AP chest X-ray did not reveal any metastatic lesions. Similarly, abdominal ultrasound did not show any focal lesions in the parenchymal organs.

After a GP consultation, in general anesthesia, using median cervical flap, the patient underwent a selective lymph node dissection in levels I, II, III on the side of the lesion (left side supraomohyoid neck dissection SOHND). For the purpose of intraoperative histological examination, a lymph node located between levels III and IV was dissected. It did not reveal any metastatic lesions, therefore lymphadenectomy in levels III and IV was not performed. Redon drain was used, and multiple layer suturing was applied. The second stage involved a partial resection of the left maxilla, along with a complete removal of the epithelial lining of the left maxillary sinus. The surgery was performed via intraoral approach. The defect was filled with a prosthodontic impression material and a palatal plate was fixed with two screws to the maxilla on the contralateral side. Due to a clean-contaminated type of the surgery, the antibiotic prophylaxis (amoxiclav $1.2 \mathrm{gr}$ i.v.) was administered intraoperatively.

There were no post-operative complications. The patient was discharged in good general and local condition 72 hours after the surgery.

Histopathological examination of the intraoperative specimen did not show any metastases in 25 lymph nodes found in the sample $(0 / 25)$. The examination of the maxilla specimen revealed that in the left site after the cyst removal there was an abscess surrounded by unspecific granulation tissue along with purulent inflammatory infiltration, edema, and mucosal hyperemia. Neither the sample nor its borders showed the presence of carcinoma infiltration.

Having received histopathological examination results of the surgical specimen and following the oncological council consultation, it was decided not to qual-

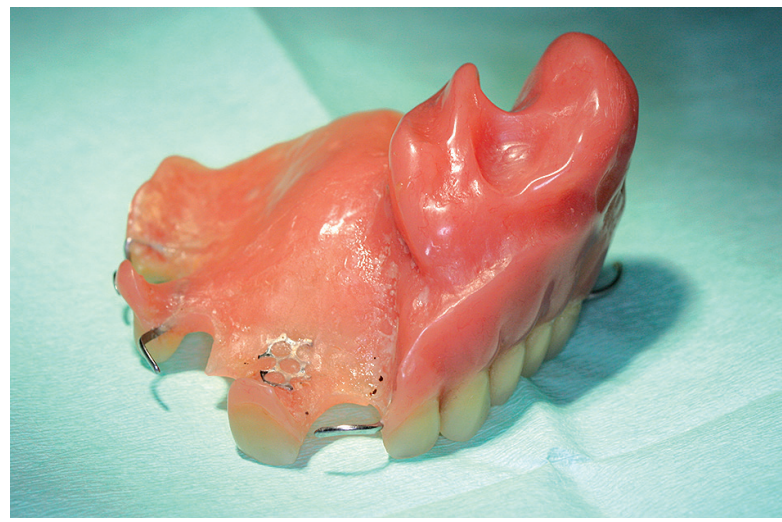

FIGURE 12. Obturator

ify the patient for the adjuvant radiotherapy. The patient remains in the frequent follow-up in the outpatient care of the Craniomaxillofacial Surgery Department with no symptoms of locoregional recurrence (Figure 11). He has been using a post-resection prosthesis (Figure 12).

Six months after the surgery, diagnostic imaging (spiral CT scan of the facial skeleton) did not show any lesions suggesting local recurrence or lymph nodes metastases.

\section{DISCUSSION}

Central mucoepidermoid carcinoma appears extremely rarely. According to Li et al. and Munde et al., since 1952, there have been only 140 such cases reported $[13,14]$. The percentage of publications describing CMEC constitutes about 2-4\% of all published cases of MEC [4]. The vast majority of CMEC are low-grade tumors - according to Kochaji et al., they appear almost 5 times more frequently than high-grade types [6].

Most of CMEC cases involved patients who sought for a medical help due to signs or symptoms of an ongoing pathological process. Clinical symptoms of CMEC are usually strictly connected with tumor localization. The most common signs and symptoms are: asymmetry caused by intraosseous expansion [3, 6, 8-12, 15-23], pain [3, 8-11, 18-23], higher tooth mobility [24], trismus [8, 24], and bleeding [23]. The following are less frequently mentioned in the literature $[11,22,24]$ : nasal congestion [17], headaches [17], tinnitus [10, 25], loss of hearing [25], or diplopia [20], when it comes to the maxilla. In case of the mandible, high-grade tumors were causing paresthesia along with hypoesthesia of the lower lip and teeth (Vincent symptom) [23, 26]. All of the above-mentioned signs and symptoms are associated with advanced clinical stage of tumors. Pathological mandibular fracture is also possible; however, no such case has ever been documented. Additionally, clinical symptoms depend on the locoregional stage. After exceeding bony rims, the tumor infiltrates surrounding soft tissues and 
when it reaches significant size, it causes facial asymmetry. Locoregional metastases usually present in neck lymph nodes [5, 8, 22]. Intraoral examination of our patient showed only the elevation caused by expansion of the alveolar process of the left maxilla. No metastases to regional lymph nodes were discovered. Nevertheless, it must be emphasized that the tumor was detected accidentally during radiological examination. Intraoral examination revealed a palpable expansion near the alveolar process of the left maxilla along with a thinning of the cortical plate, but these had been overlooked during previous dental check-ups. Due to this omission, the patient could not have been diagnosed correctly at an earlier stage of the disease.

There are no radiological pathognomonic signs of CMEC. Radiological image usually presents a unior multilocular radiolucency with well-defined borders $[5,6,8]$. In some CMEC cases, osteolysis on the cavity margin was observed along with its receding contours. Although there are rare cases of CMEC reported with no intraosseous expansion (mostly in less advanced tumors), in the vast majority of published cases, CT scans detect this sign [6]. In case of CMEC located within the maxilla, an invasion into surrounding anatomical spaces, mostly the maxillary sinus and/or nasal cavity is observed. When carcinoma develops in the alveolar process of the maxilla or the alveolar part of the mandible, it often causes gomphiasis [25].

From radiological perspective, CMEC must be definitely differentiated from odontogenic cysts and tumors (mostly ameloblastoma, myxoma, and keratocystic odontogenic tumor) as well as primary intraosseous carcinomas $[8,24]$. Odontogenic cysts are, in most cases, unilocular and present well-defined borders, while odontogenic carcinomas and some carcinoma-like tumors, might show multilocular defects of bone structure with blurry contours at times. Extremely rare primary intraosseous squamous cell carcinoma usually projects in the form of blurry contours of bone structure defect, with visible osteolysis on its margin. The Stafne defect, which may also need to be differentiated from CMEC, is almost always localized below the mandibular canal, while CMEC usually occurs above this part.

The most popular diagnostic criteria of CMEC were proposed by Alexander et al. in 1974 and later modified by Browand and Waldron [5]. They include: 1) an intact cortical plate; 2) radiological evidence of bone destruction; 3) exclusion of another primary intraosseous tumor; 4) histopathological confirmation of CMEC.

In 1990, Brookstone et al. [27] presented a staging system for CMEC, which was based on the condition of the overlying bone: Stage 1 - Lesions with intact cortical plates with no evidence of bone expansion; Stage 2 Tumors with intact plates but palpable intraosseous expansion; Stage 3 - All lesions associated with cortical plates, breakdown of the overlying periosteum or nodal disease. In the presented case, "egg shell cracking" was clinically palpable, and in a small area, it was also possible to feel some fluctuation, which proved that cortical layer of the bone was perforated. After separating the mucoperiosteal flap, destruction of a cortical plate became visible in a significant area. All these signs allow this case to be qualified as stage 3 according to Brookstone et al.

From morphological perspective, low-grade central mucoepidermoid carcinoma is similar to glandular odontogenic cyst (GOC), an extremely rare lesion with a high tendency of recurrence and aggressive potential. Such a cyst may transform into CMEC. This fact may cause numerous difficulties in diagnosis, which, in turn, may influence choosing the appropriate way of treatment: less radical in case of glandular cyst or more aggressive in case of carcinoma [28-31].

Histological diagnosis of high-grade mucoepidermoid carcinoma developing in an odontogenic cyst requires differential diagnosis from other intraosseous lesions, which may be similar to a cyst in clinical examinations. Morphological features of the epithelial lining provide the grounds for eliminating odontogenic cysts. Epithelium of true cysts of maxillary bones is not atypical, therefore dentigerous, radicular, or orthokeratotic cysts might be easily excluded. However, some doubts might appear when it comes to differentiating a glandular odontogenic cyst, which in morphological image shows a significant similarity to low-grade mucoepidermoid carcinoma. Nevertheless, such difficulties did not appear in the presented case due to a considerable atypia of the epithelial lining cells of the cyst and signs of surrounding tissues infiltration. Differential diagnosis of intraosseous malignant neoplasms also includes primary intraosseous squamous cell carcinoma developing in an odontogenic cyst as well as low-grade mucoepidermoid carcinoma. However, the presence of epidermal, intermediate, and mucus-secreting cells in the area of the lesion exclude squamous cell carcinoma, since these types of cells are typical for MEC. Differentiating between low-grade and high-grade MEC is based on the following criteria: proportion between cystic and solid tissue architecture (high-grade is dominated by solid areas), mutual proportion between particular types of in carcinomatous parenchyma (the more malignant carcinoma, the fewer mucus-secreting cells), proliferative activity as well as presence of necrosis. In this case, the areas of infiltrated fibrous tissue were dominated by solid areas of carcinoma cells of high mitotic activity, epidermal, and intermediate type, with rare mucus-secreting cells. The central portion of carcinomatous nests was necrotic with numerous granulocytes. In conclusion, diagnosis of high-grade mucoepidermoid carcinoma developing in an odontogenic cyst was based on the following criteria:

- Preserved areas of the odontogenic cyst lined with epithelium without signs of atypia;

- Presence of neoplastic transformation of the epithelial lining, marked by its significant thickening, cell layering disorder, atypical features of cells, high 
mitotic activity, without signs of infiltration of surrounding tissues;

- Presence of an area infiltrated by mucoepidermoid carcinoma showing typical features of high-grade carcinoma.

CMEC unarguably requires surgical treatment. There are experts who take into consideration the possibility of less radical surgical procedure involving enucleation or curettage of the lesion (with or without adjuvant radiotherapy). However, such a way of treatment entails high-risk of recurrence $(40-45 \%)$ [5, 18], while radical surgical procedure (bone resection) decreases this risk to the level of $13 \%[5,18]$. The 5 -year survival rate of a low-grade tumor is $95 \%$ but in case of a high-grade tumor, it declines to $40 \%$ [32]. Freje et al. recommends radiotherapy in high-grade tumors and neck dissection in a case of metastases in regional lymph nodes [33].

Patients require a long-term and regular clinical and radiological follow-up in order to exclude a potential recurrence or metastases, which appears in 9\% of CMEC cases, mostly to regional lymph nodes, clavicle, lungs, or brain [18].

Clinical and radiological image of the presented case points out that the main cause of carcinoma development was a neoplastic transformation of the epithelial lining of an odontogenic cyst, likely of dentigerous (similar microscopic image of both lesions [28-31]) or radicular type.

\section{CONCLUSIONS}

Central mucoepidermoid carcinoma appears extremely rarely. Histologically, low-grade lesions with higher survival rate are more frequently found than rare highgrade cases. Taking into consideration the possibility of a malignant transformation of the epithelial lining of odontogenic cysts, it is crucial to conduct a histopathological examination of the whole lining of pathological lesions after enucleation or curettage. This gives a chance to detect a potential neoplastic transformation and to implement appropriate treatment at an early stage.

\section{CONFLICT OF INTEREST}

The authors declare no potential conflicts of interest with respect to the research, authorship, and/or publication of this article.

\section{References}

1. Stewart FW, Foote FW, Becker WF. Muco-epidermoid tumors of salivary glands. Ann Surg 1945; 122: 820-844.

2. Lepp H. Zur kenntnis des papillar wachsenden schleimigen cystadenokarzinoms der mundhohle. Ziegler's Beitrage Z Pathol Anat 1939; 102: 164-166.

3. Simon D, Somanathan T, Ramdas K, Pandey M. Central mucoepidermoid carcinoma of mandible - a case report and review of the literature. World J Surg Oncol 2003; 1: 1.
4. Raut DL, Khedkar SA. Primary intraosseous mucoepidermoid carcinoma of the maxilla: a case report and review of literature. Dentomaxillofacial Radiol 2009; 38: 163-168.

5. Browand BC, Waldron CA. Central mucoepidermoid tumors of the jaws. Report of nine cases and review of the literature. Oral Surg Oral Med Oral Pathol 1975; 40: 631-643.

6. Kochaji N, Goossens A, Bottenberg P. Central Mucoepidermoid carcinoma: case report, literature review for missing and available information and guideline proposal for coming case reports. Oral Oncol Extra 2004; 40: 95-105.

7. Huvos AG, Brookstone MS. Central salivary gland tumors of the maxilla and mandible: a clinicopathologic study of 11 cases with an analysis of the literature. J Oral Maxillofac Surg 1992; 50: 229-236.

8. Pires FR, Paes de Almeida O, Lopes MA, et al. Central mucoepidermoid carcinoma of the mandible: report of four cases with long-term follow-up. Int J Oral Maxillofac Surg 2003; 32: 378-382.

9. Aggarwal P, Saxena S. Aggressive growth and neoplastic potential of dentigerous cysts: with particular reference to central mucoepidermoid carcinoma. Br J Oral Maxillofac Surg 2011; 49: e36-e39.

10. Sepúlveda I, Frelinghuysen M, Platin E, et al. Mandibular central mucoepidermoid carcinoma: A case report and review of the literature. Case Rep Oncol 2014; 7: 732-738.

11. Kechagias N, Ntomouchtsis A, Mavrodi A, et al. Central mucoepidermoid carcinoma of the anterior region of the mandible: report of an unusual case and review of the literature. Oral Maxillofac Surg 2015; 19: 309-313.

12. Sherin S, Sherin N, Thomas V, et al. Central mucoepidermoid carcinoma of maxilla with radiographic appearance of mixed radiopaque-radiolucent lesion: a case report. Dentomaxillofacial Radiol 2011; 40: 463-465.

13. Munde A, Karle R, Metgud R, Rudgi B. Central mucoepidermoid carcinoma of the mandible. Indian J Dent Res 2010; 21: 609-610.

14. Li Y, Li LJ, Huang J, et al. Central malignant salivary gland tumors of the jaw: retrospective clinical analysis of 22 cases. J Oral Maxillofac Surg 2008; 66: 2247-2253.

15. Atarbashi Moghadam S, Atarbashi Moghadam F. Intraosseous mucoepidermoid carcinoma: report of two cases. J Dent 2014; 15 : 86-90.

16. Tucci R, Matizonkas-Antonio LF, De Carvalhosa AA, et al. Central mucoepidermoid carcinoma: report of a case with 11 years' evolution and peculiar macroscopical and clinical characteristics. Med Oral Patol Oral Cir Bucal 2009; 14: 11-14.

17. Namin AK, Moshref M, Shahoon H, et al. Intraosseous mucoepidermoid carcinoma of the maxilla in a teenager: a case report and review of literature. Oral Surg Oral Med Oral Pathol Oral Radiol Endod 2005; 100: 93-96.

18. Takano M, Kasahara K, Matsui S, et al. A case of mucoepidermoid carcinoma associated with maxillary cyst. Bull Tokyo Dent Coll 2012; 53: 119-125.

19. De Mello-Filho FV, Brigato RR, Mamede RCM, et al. Central mucoepidermoid carcinoma: report of 2 cases. Br J Oral Maxillofac Surg 2008; 46: 239-241.

20. Suresh D, Raviraj J, Vijaykumar B, et al. Central mucoepidermoid carcinoma of the maxilla with unusual ground glass appearance and calcifications: a case report. Imaging Sci Dent 2014; 44: 161-164.

21. Spoorthi BR, Rao RS, Rajashekaraiah PB, et al. Predominantly cystic central mucoepidermoid carcinoma developing from a previously diagnosed dentigerous cyst: case report and review of the literature. Clin Pract 2013; 3: e19.

22. Maremonti P, Califano L, Mangone GM, et al. Intraosseous mucoepidermoid carcinoma. Report of a long-term evolution case. Oral Oncol 2001; 37: 110-113.

23. Lei J, Xiao-Zhong J, Liang-Yu Z, et al. Central mucoepidermoid carcinoma of the jaws: report of two cases. J Med Coll PLA 2007; 22: 129-131.

24. He Y, Wang J, Fu HH, et al. Intraosseous mucoepidermoid carcinoma of jaws: report of 24 cases. Oral Surg Oral Med Oral Pathol Oral Radiol 2012; 114: 424-429. 
25. Ollero JM, Morón AH, Luis ÁM, et al. Nasopharyngeal mucoepidermoid carcinoma: a case report and review of literature. Reports Pract Oncol Radiother 2012; 18: 117-120.

26. Chiu GA, Woodwards RT, Benatar B, Hall R. Mandibular central mucoepidermoid carcinoma with distant metastasis. Int J Oral Maxillofac Surg 2012; 41: 361-363.

27. Brookstone MS, Huvos AG, Spiro RH. Central adenoid cystic carcinoma of the mandible. J Oral Maxillofac Surg 1990; 48: 1329 1333.

28. Bishop JA, Yonescu R, Batista D, et al. Glandular odontogenic cysts (GOCs) lack MAML2 rearrangements: a finding to discredit the putative nature of GOC as a Precursor to Central Mucoepidermoid Carcinoma. Head Neck Pathol 2014; 8: 287-290.

29. Noffke C, Raubenheimer EJ. The glandular odontogenic cyst: clinical and radiological features; review of the literature and report of nine cases. Dentomaxillofac Radiol 2002; 31: 333-338.

30. Mucha G, Uryga D, Namysłowski P, et al. Zębopochodna torbiel gruczołowa imitująca okołowierzchołkową torbiel korzeniową - opis przypadku i przegląd piśmiennictwa. Endodoncja Prakt 2016; 2: 7-13.

31. Prabhu S, Rekha K, Kumar G. Glandular odontogenic cyst mimicking central mucoepidermoid carcinoma. J Oral Maxillofac Pathol 2010; 14: 12-15.

32. Nallamilli SM, Tatapudi R, Reddy RS, et al. Primary intraosseous mucoepidermoid carcinoma of the maxilla. Ghana Med J 2015; 49: $120-123$.

33. Freje JE, Campbell BH, Yousif N J, Clowry LJ. Central mucoepidermoid carcinoma of the mandible. Otolaryngol Head Neck Surg 1995; 112: 453-456. 